\title{
Environmental Fluctuations and Acoustic Data Communications
}

\author{
W.S. Hodgkiss and H.C. Song \\ Marine Physical Laboratory \\ Scripps Institution of Oceanography \\ La Jolla, CA 92093-0701 \\ phone: (858) 534-1798/0954 / fax: (858) 822-0665 \\ email: whodgkiss@ucsd.edu / hcsong@ucsd.edu
}

Award Number: N00014-11-1-0364

http://www.mpl.ucsd.edu

\section{LONG-TERM GOALS}

Couple together analytical and numerical modeling of oceanographic and surface wave processes, acoustic propagation modeling, statistical descriptions of the waveguide impulse response between multiple sources and receivers, and the design and performance characterization of underwater acoustic digital data communication systems in shallow water.

\section{OBJECTIVES}

Develop analytical/numerical models, validated with experimental data, that relate short-term oceanographic variability and source/receiver motion to fluctuations in the waveguide acoustic impulse response between multiple sources and receivers along with new communication receiver algorithms that exploit these channel characterizations.

\section{APPROACH}

The focus of this research is on how to incorporate an understanding of short-term variability in the oceanographic environment and source/receiver motion into the design and performance characterization of underwater acoustic, diversity-exploiting, digital data communication systems. The underlying physics must relate the impact of a fluctuating oceanographic environment and source/receiver motion to fluctuations in the waveguide acoustic impulse response between multiple sources and receivers and ultimately to the design and performance characterization of underwater acoustic digital data communication systems in shallow water.

The two major thrusts of this work include participation in a shallow water acoustic communication experiment in June-July 2011 along with subsequent analysis of the experiment data.

\section{KAM11 Experiment (2011)}

A shallow water acoustic communications experiment (KAM11) was carried out in June-July 2011 off the western side of Kauai, Hawaii at the Pacific Missile Range Facility (PMRF). Both fixed and towed source transmissions were carried out to multiple receiving arrays over ranges of approximately 1-14 $\mathrm{km}$. Substantial environmental data was collected including water column sound speed structure 


\section{Report Documentation Page}

Form Approved

OMB No. 0704-0188

Public reporting burden for the collection of information is estimated to average 1 hour per response, including the time for reviewing instructions, searching existing data sources, gathering and maintaining the data needed, and completing and reviewing the collection of information. Send comments regarding this burden estimate or any other aspect of this collection of information,

including suggestions for reducing this burden, to Washington Headquarters Services, Directorate for Information Operations and Reports, 1215 Jefferson Davis Highway, Suite 1204, Arlington

VA 22202-4302. Respondents should be aware that notwithstanding any other provision of law, no person shall be subject to a penalty for failing to comply with a collection of information if it

does not display a currently valid OMB control number.

1. REPORT DATE

30 SEP 2014

4. TITLE AND SUBTITLE

Environmental Fluctuations and Acoustic Data Communications

6. AUTHOR(S)

7. PERFORMING ORGANIZATION NAME(S) AND ADDRESS(ES)

University of California San Diego,Scripps Institution of Oceanography,9500 Gilman Drive,La Jolla,CA,92093

9. SPONSORING/MONITORING AGENCY NAME(S) AND ADDRESS(ES)

\section{DATES COVERED}

00-00-2014 to 00-00-2014

5a. CONTRACT NUMBER

5b. GRANT NUMBER

5c. PROGRAM ELEMENT NUMBER

5d. PROJECT NUMBER

5e. TASK NUMBER

5f. WORK UNIT NUMBER

8. PERFORMING ORGANIZATION REPORT NUMBER

10. SPONSOR/MONITOR'S ACRONYM(S)

11. SPONSOR/MONITOR'S REPORT NUMBER(S)

12. DISTRIBUTION/AVAILABILITY STATEMENT

Approved for public release; distribution unlimited

13. SUPPLEMENTARY NOTES

14. ABSTRACT

15. SUBJECT TERMS

16. SECURITY CLASSIFICATION OF:

a. REPORT

unclassified b. ABSTRACT

unclassified c. THIS PAGE

unclassified
17. LIMITATION OF ABSTRACT

Same as

Report (SAR)
18. NUMBER 19a. NAME OF

OF PAGES RESPONSIBLE PERSON

6 
(CTDs and thermistor strings), sea surface directional wave field (waverider buoy), and local wind speed and direction. The focus was on fluctuations over scales of a few seconds to a few tens of seconds that directly affect reception of a data packet and packet-to-packet variability.

\section{Algorithm Design and Experiment Data Analysis}

Communication receiver algorithm design for shallow water is challenging due to the likelihood of encountering highly dynamic environments. In fact, one of the reasons for the KAM11 site selection was the variability of the environmental conditions (both sea surface and water column) from fairly calm to highly fluctuating. One emphasis of our work is mitigating Doppler and Doppler spread (both due to source-receiver motion as well as a fluctuating sea surface). Another emphasis of our work is multi-user receiver design in the presence of unsynchronized users (to accommodate networked communication). Lastly, a third emphasis of our work is communication algorithm design for very low signal-to-noise ratio (SNR) operations.

\section{WORK COMPLETED}

A shallow water acoustic communications experiment (KAM11) was conducted in early summer 2011 off the western side of Kauai, Hawaii [8]. Both fixed and towed source transmissions were carried out to multiple receiving arrays over ranges of 1-8 $\mathrm{km}$ along with additional towed source transmissions out to $14 \mathrm{~km}$ range. The acoustic transmissions were in three bands covering 3.5 to $35 \mathrm{kHz}$. Substantial environmental data was collected including water column sound speed structure (CTDs and thermistor strings), sea surface directional wave field (waverider buoy), and local wind speed and direction. The focus was on fluctuations over scales of a few seconds to a few tens of seconds that directly affect the reception of a data packet and packet-to-packet variability. The experiment region exhibited substantial daily oceanographic variability.

Analysis of the KAM11 experiment data this past year has focused on fixed source transmissions. Specifically, data investigating the influence of surface interacting ray paths compared to refracting ray paths was analyzed.

Publications related to this research involving analysis of KAM11 (and previous KAM08) data include [1-14].

\section{RESULTS}

During KAM11, a two-day period was devoted to wideband transmissions. Specifically, wideband channel impulse response transmissions ( $24 \mathrm{kHz}$ bandwidth LFM chirps and MLSs centered at $23 \mathrm{kHz}$ ) were carried out every 2 hours for an extended period of time. These were transmitted from a moored 8-element source array with $7.5 \mathrm{~m}$ element spacing and carried out in a round-robin fashion for $60 \mathrm{~s}$ per source element. A pair of 16-element receive arrays with $3.75 \mathrm{~m}$ element spacing were moored at ranges of 3 and $7 \mathrm{~km}$ from the source array (see Fig. 1). The fixed source, fixed receiving array geometry enabled observing environmentally-induced fluctuations in the channel impulse response $[11,14]$.

The multipath structure at 0351 UTC predicted using the Bellhop ray tracing code from Source 1 to Receivers 1 and 3 is shown in Fig. 2. The sound speed profile has a mixed layer depth of $\sim 35 \mathrm{~m}$ then a negative gradient thermocline extending to the bottom. As a result, higher-angle ray paths interact with 
the sea surface while lower-angle ray paths are ducted as near-seafloor refracting rays. The single surface reflecting paths arrive first at the array while the deep refracting rays arrive later.

The wideband (10-34 kHz LFM chirps, $48 \mathrm{~ms}$ in duration repeated every $96 \mathrm{~ms}$ ) time-evolving (over $60 \mathrm{~s}$ ) channel impulse response (CIR) is shown in Fig. 3 for the deepest source (Source 1) to two deep receiving array elements (Receivers 1 and 3) at a range of $3 \mathrm{~km}$ from the source array. The first few arrivals (44-47 ms) correspond to single surface-reflecting paths (the bulk travel time has been removed from these CIR plots). In an effort to remove any residual mooring motion, Fig. 3 is obtained from resampled time series data using as a reference the deep refracting paths arriving at $48.43 \mathrm{~ms}$ and $48.21 \mathrm{~ms}$, respectively. The relatedness of fluctuations between pairs of paths is summarized by the path-path covariance matrices. These are shown in Fig. 4 for the individual receivers and in Fig. 5 for the cross-receiver case. These covariance matrices then can be used for tapped delay line channel model simulation purposes [3].

\section{IMPACT / APPLICATIONS}

Acoustic data communications is of broad interest for the retrieval of environmental data from in situ sensors, the exchange of data and control information between AUVs (autonomous undersea vehicles) and other off-board/distributed sensing systems and relay nodes (e.g. surface buoys), and submarine communications.

\section{RELATED PROJECTS}

In addition to other ONR Code 322OA and Code 321US projects investigating various aspects of acoustic data communications from both an ocean acoustics and signal processing perspective, two recently completed MURIs also focused on acoustic communications (W. Hodgkiss, "Impact of Oceanographic Variability on Acoustic Communications" and J. Preisig, "Underwater Acoustic Propagation and Communications: A Coupled Research Program”).

\section{PUBLICATIONS}

[1] S. Cho, H.C. Song, and W.S. Hodgkiss, "Successive interference cancellation for underwater acoustic communications,” IEEE J. Oceanic Engr. 36(4): 490-501, DOI: 10.1109/JOE.2011.2158014 (2011). [published, refereed]

[2] H.C. Song, "Time reversal communication in a time-varying sparse channel," J. Acoust. Soc. Am. 130(4): EL161-EL166, DOI: 10.1121/1.3629138 (2011). [published, refereed]

[3] Y. Isukapalli, H.C. Song, and W.S. Hodgkiss, "Stochastic channel simulator based on local scattering functions," J. Acoust. Soc. Am. 130(4): EL200-EL205, DOI: 10.1121/1.3633688 (2011). [published, refereed]

[4] T. Kang, H.C. Song, and W.S. Hodgkiss, "Multi-carrier synthetic aperture communication in shallow water: Experimental results," J. Acoust. Soc. Am. 130(6): 3797-3802, DOI: 10.1121/3652855 (2011). [published, refereed]

[5] S. Cho, H.C. Song, W.S. Hodgkiss, "Multiuser interference cancellation in time-varying channels," J. Acoust. Soc. Am. 131(2): EL163-EL169, DOI: 10.1121/1.3678668 (2012). [published, refereed] 
[6] H.C. Song, "Bidirectional equalization for underwater acoustic communication," J. Acoust. Soc. Am. 131(4): EL343-EL347, DOI: 10.1121/1.3695075 (2012). [published, refereed]

[7] S. Cho, H.C. Song, and W.S. Hodgkiss, “Asynchronous multiuser underwater acoustic communications (L),” J. Acoust. Soc. Am. 132(1): 5-8, DOI: 10.1121/1.4726029 (2012). [published, refereed]

[8] W.S. Hodgkiss and J.C. Preisig, "Kauai Acomms MURI 2011 (KAM11) Experiment,” Proc. 11th European Conference on Underwater Acoustics (ECUA): 1-8 (2012). [published]

[9] S. Cho, H.C. Song, and W.S. Hodgkiss, "Multiuser acoustic communications with mobile users," J. Acoust. Soc. Am. 133(2): 880-890, DOI: 10.1121/1.4773267 (2013). [published, refereed]

[10] H.C. Song and W.S. Hodgkiss, "Efficient use of bandwidth for underwater acoustic communication (L),” J. Acoust. Soc. Am. 134(2): 905-908, DOI: 10.1121/1.4812762 (2013). [published, refereed]

[11] W.S. Hodgkiss, H.C. Song, and D.E. Ensberg, "Wideband channel impulse response fluctuations in shallow water," Proc. $1^{\text {st }}$ Intl. Conf. Underwater Acoustics (UA) 2013: 1565-1570, ISBN 978-61880725-0-3 (2013). [published]

[12] H.C. Song, "Equivalence of adaptive time reversal and least squares for cross talk mitigation," J. Acoust. Soc. Am. 135(3): EL154-EL158, DOI: 10.1121/1.4865839 (2014). [published, refereed]

[13] Y. Choo, W. Seong, and H.C. Song, "Emergence of striation patterns in acoustic signals reflected from dynamic surface waves,” J. Acoust. Soc. Am. 136(3): 1046-1053 (2014). [published, refereed]

[14] W.S. Hodgkiss, H.C. Song, and D.E. Ensberg, "Statistical characterization of wideband channel impulse response observations in shallow water," Proc. $2^{\text {nd }}$ Intl. Conf. Underwater Acoustics (UA2014): 1535-1540, ISBN: 978-618-80725-1-0 (2014). [published]

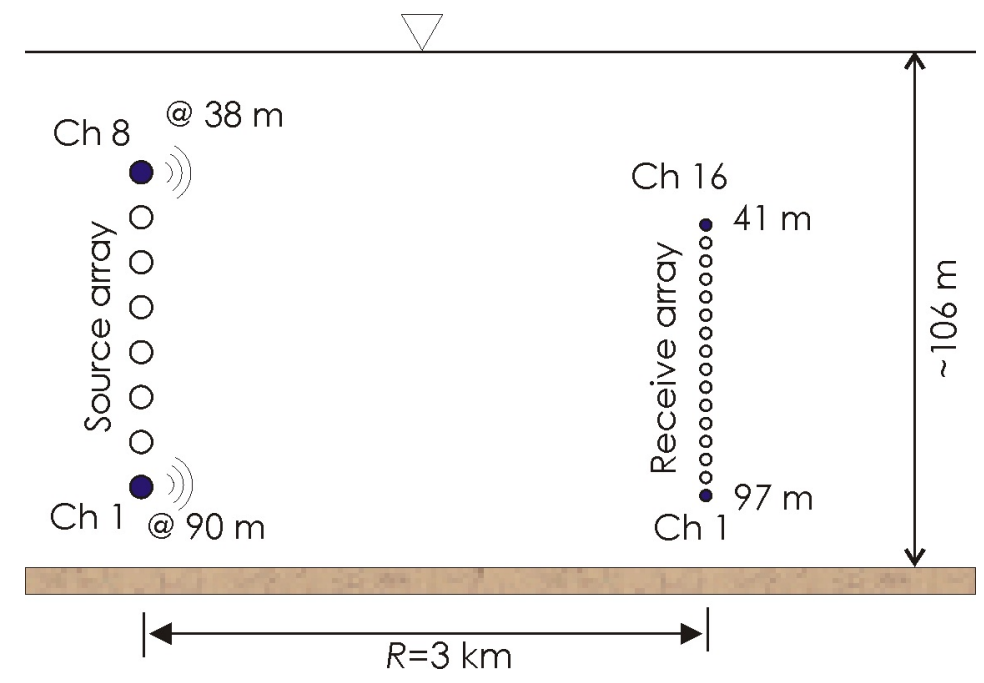

Figure 1. KAM11 experiment source and receive array $(R=3 \mathrm{~km})$ configuration during collection of wideband transmission data. Source array element spacing was $7.5 \mathrm{~m}$ and receive array element spacing was $3.75 \mathrm{~m}$. 

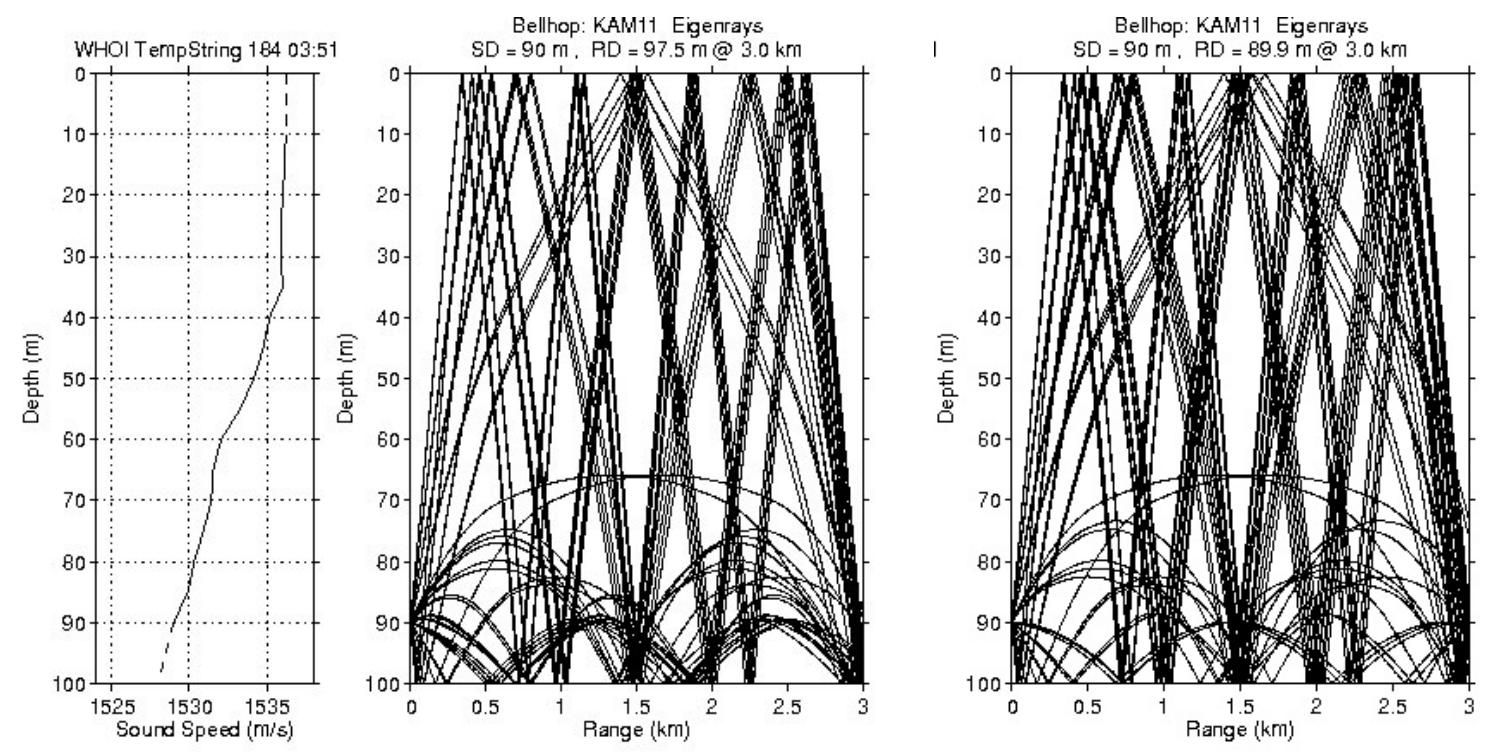

Figure 2. Multipath structure at 0351 UTC on JD 184: (a) sound speed profile, (b) eigenray paths from Source 1 to Receiver 1, and (c) eigenray paths from Source 1 to Receiver 3. The single surface reflecting paths arrive first at the array while the deep refracting rays arrive later.
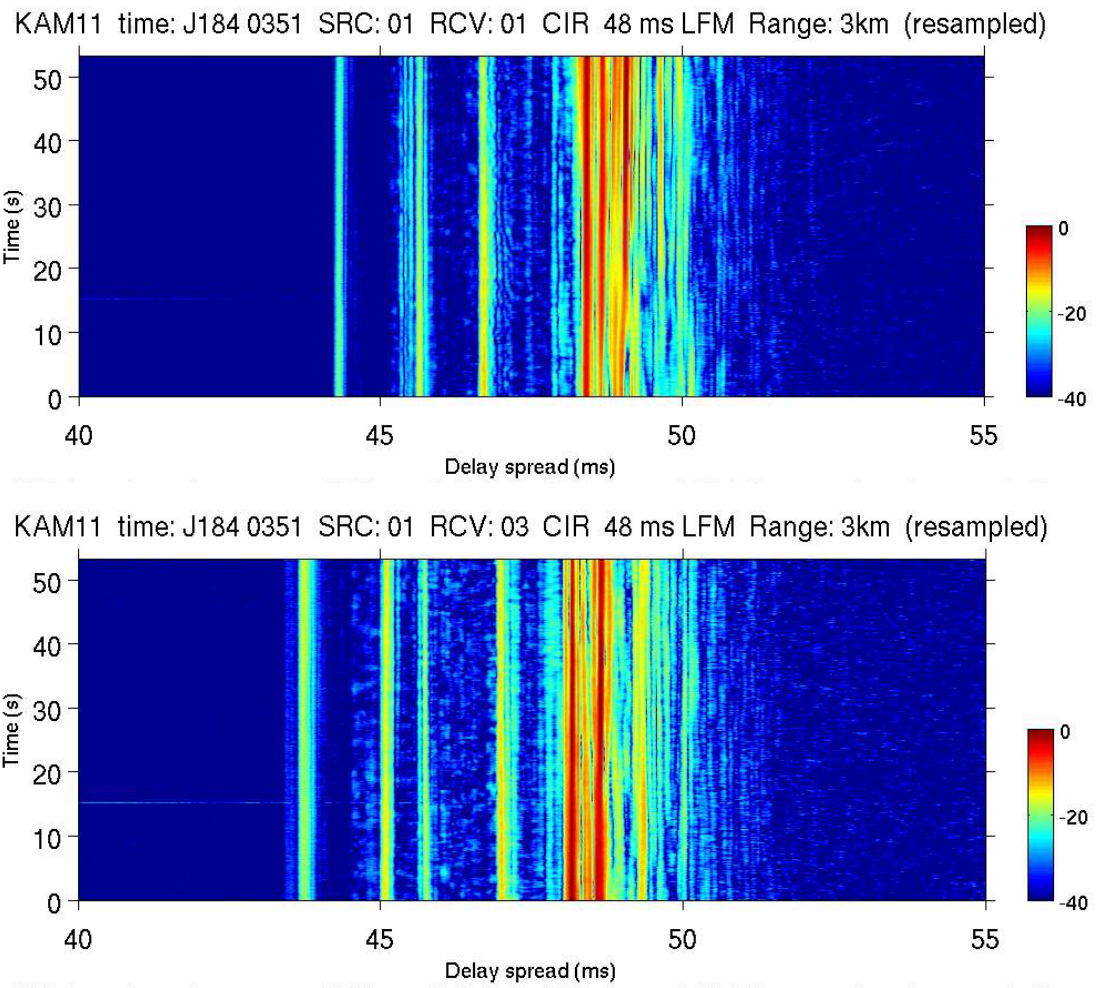

Figure 3. Wideband time-evolving channel impulse response on JD 1840351 UTC: (a) Source 1 to Receiver 1 and (b) Source 1 to Receiver 

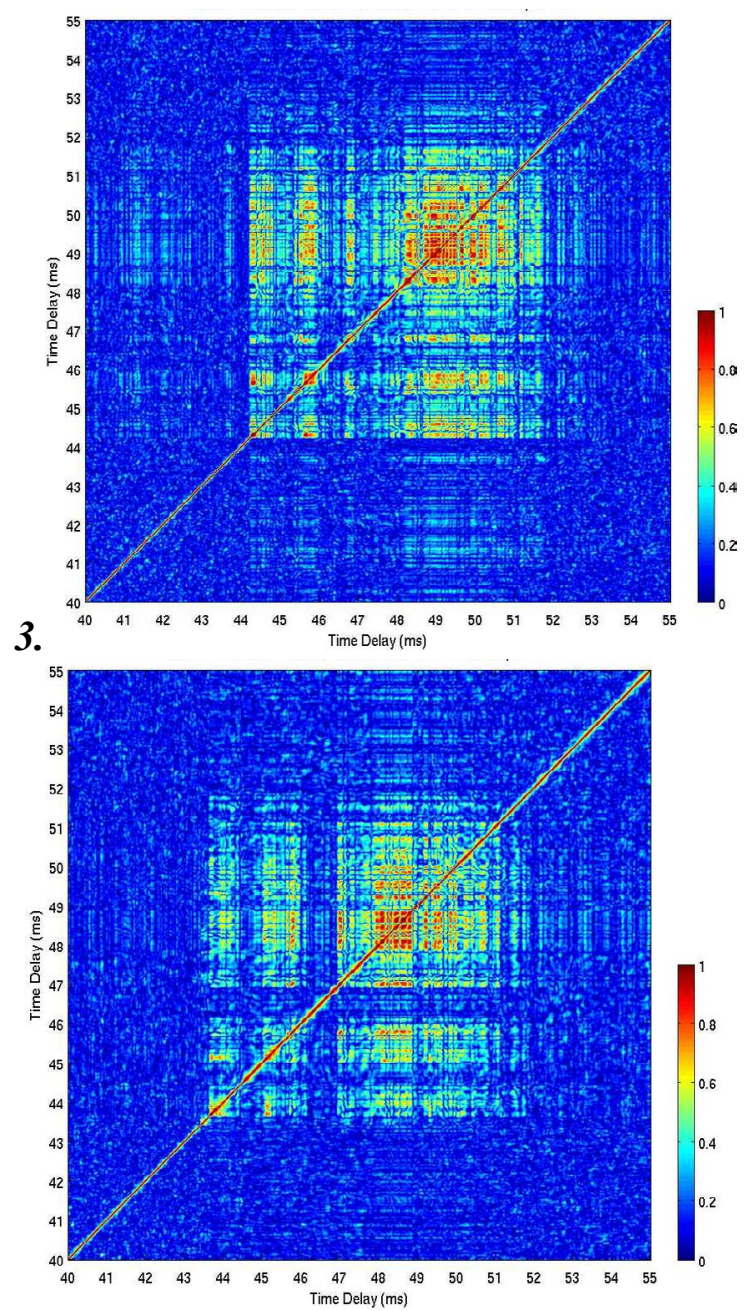

Figure 4. Wideband path-path normalized covariance matrix on JD 1840351 UTC: (a) Receiver 1 and (b) Receiver 3.

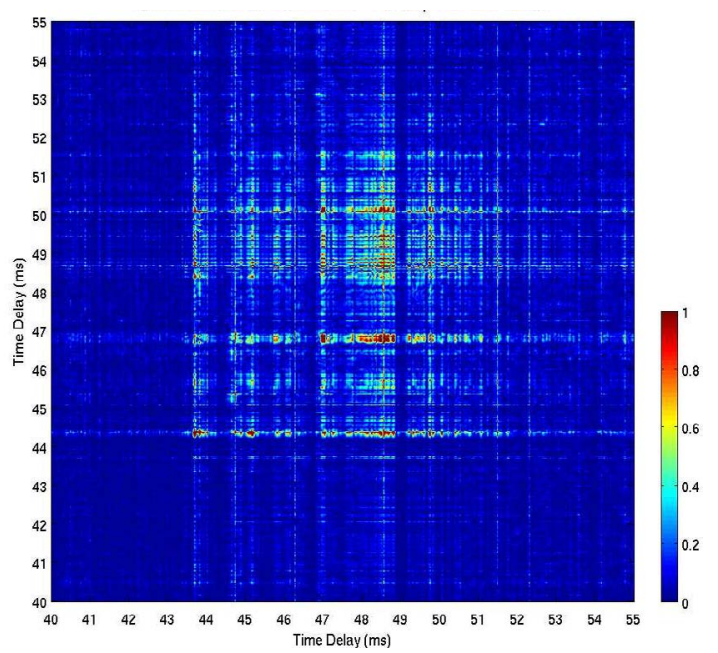

Figure 5. Wideband path-path normalized cross-covariance matrix on JD 1840351 UTC: Receiver 1 (vertical axis) and Receiver 3 (horizontal axis). 